\title{
How Disgust Affects Romantic Attraction: the Influence of Moods on Judgments of Attractiveness
}

\author{
Nicholas Phelan $^{1}$ • John E. Edlund ${ }^{1}$ \\ Published online: 24 September 2015 \\ (C) Springer International Publishing 2015
}

Research has shown that facial disfigurements are seen as less attractive in a potential mate, especially if they resemble a disfigurement associated with a contagious disease as opposed to a "battle" scar (e.g., Houston and Bull 1994; Kurzban and Leary 2001; Ryan, Oaten, Stevenson, and Case 2012). Facial attraction research has also demonstrated that facial disfigurements can impact facial symmetry along with how prototypical a face looks, both of which are factors in how attractive a face is (e.g., Halberstadt and Rhodes 2000; Johnson, Hagel, Franklin, Fink, and Grammer 2001; Penton-Voak et al. 2001; Schieb, Gangestead, and Thornhill 1999).

Oaten et al. (2009) have a number of hypotheses of disgust perception and disgust violations they discuss in support of the disease avoidance hypothesis. The hypotheses proposed by Oaten et al. (2009) examine violations of cultural norms when it comes to disease-related objects and practices.

For instance, it has been demonstrated that people will generally avoid others who have prominent facial scars or disfigurements (Houston and Bull 1994). The disease avoidance hypothesis suggests this occurs because the person with the facial disfigurement elicits disgust in us and this in turn triggers an avoidance reaction. Park et al. (2003) hypothesized that facial disfigurements are directly linked to some of the more contagious and deadly diseases. Diseases like smallpox, leprosy, and the bubonic plague all have skin blemishes as one of the main symptoms. It is believed that because of these types of diseases we have adapted to avoid individuals who have skin conditions like those that occur when someone has contracted a communicable disease. This research provides a foundation for an evolutionary model of disease avoidance and a link between disease avoidance and disgust.

Ryan et al. (2012) looked for empirical evidence to show that disgust is a moderator of disease avoidance. They showed participants videos of confederates handling props that the participants had to interact with later in the study. The 
confederates either were healthy, had a facial disfigurement, or exhibited signs of having the flu such as a runny nose, coughing, and sneezing. The researchers found that participants were more disgusted with the props after the confederates with the flu or the facial disfigurement handled them. The participants exhibited greater facial reactions, like crinkled noses and big eyes, indicating disgust, and many participants refused to touch the props. This provides strong evidence that disgust is a moderator in the disease avoidance process and that a facial disfigurement produces a similar response as the response to an individual with a communicable pathogen.

Another research study conducted by Tybur et al. (2009) suggests that disgust solves three different adaptive problems of humans including the domains of pathogen avoidance, social interaction, and most importantly to the current study, mate choice. The research confirmed that disgust and sensitivity to it is broken up into these three domains and that individual differences affect how people react to each of the three domains. Further research suggests that the behaviors that help us avoid pathogens have been co-opted into our sexual avoidance processes because of the many different types of risks present in sexual contact and how selective humans need to be when selecting a mate (Tybur, Lieberman, Kurzban, DeScioli, 2013). This research goes to show that disgust plays a direct role in mate selection and that it is tied into our disease avoidance system.

Another hypothesis outlined by Oaten et al. (2009) predicts that women would have stronger disgust responses to diseaserelevant stimuli, due to the higher cost to women in mate selection and reproduction (if they were to get infected with a disease). If facial scars represent disease-relevant stimuli, the hypothesis presented by Oaten et al. (2009) suggests that there would be stronger reactions to facial disfigurements by women and weaker reactions by men. Kleck and Strenta (1985) examined the reaction of both men and women when looking upon facially disfigured individuals. Participants viewed pictures of themselves and other people both with and without facial disfigurements while having their galvanic skin response (GSR) measured. At the same time, participants were also asked to describe their emotional reaction to the faces. Although there was no gender difference in GSR, women expressed their disgust using stronger emotional adjectives. This study shows that simply putting a disfigurement on a face elicits a more visceral emotional response from women than a normal face and that men and women react similarly physiologically to facial disfigurements.

From this research, it is clear that facial disfigurements can cause avoidant responses similar to other disgusting stimuli like strong odors or bitter tastes. There is also evidence that facial disfigurements lead to individuals being found as less attractive than others. We have already discussed how this decreased attraction could be caused by the actual disgust response itself; however, there are other reasons why this decreased attraction could occur.

For instance, someone who is physically attractive is someone with whom we want to mate (Buss and Schmitt 1993), because it is believed a physically attractive individual has good genes that will pass on to the next generation and ensure that next generation's survival (e.g., Schieb, Gangestead, and Thornhill 1999). One of the main ways we determine someone's physical attractiveness or beauty is through their face, and there are a number of factors that determine one's level of facial attractiveness.

There are three main facets of facial attractiveness: bilateral symmetry, averageness, and sexually dimorphic facial characteristics (Fink and Penton-Voak 2002; Griffey and Little 2014). Two of these factors, averageness and bilateral symmetry, can be directly affected by facial disfigurements. The first trait we find generally attractive in faces across cultures is bilateral symmetry of the face. There have been suggestions in past research (e.g., Johnson, et al. 2001; Penton-Voak et al. 2001; Schieb et al. 1999) that symmetrical faces indicate a well-developed and healthy person and someone who has heterozygosity of their genes which is indicative of strong genetic defenses to pathogens (e.g., Schieb, Gangestead, and Thornhill 1999). We also see a correlation between averageness of faces and ratings of attraction (Fink and Penton-Voak 2002). Many studies have found that when we show people faces that have been computer generated to be average, they are rated as more attractive especially over faces with prominent features on them (Halberstadt and Rhodes 2000). To make an average face more or less attractive, there are certain features that can be manipulated. Some of these features are known as sexually dimorphic traits (Fink and Penton-Voak 2002). These traits are features that represent the hormonal health of an individual and their capability to sexually reproduce. All three of these indicators have been found to not only be simple declared preferences by humans but research has shown they are visually preferred on a subconscious level (Griffey and Little 2014). This research further cements the importance of these three traits in our judgments of facial attractiveness.

Rhodes (2006) had similar findings to Fink and PentonVoak (2002) in her meta-analyses of the research of sexually attractive facial characteristics. She found that for both men and women averageness and symmetry were important in determining how attractive an individual was. These preferences are believed to have evolved because they enhanced reproductive success and thus helped ensure the passing on of genes to the next generation. This lends support to facial attraction evolving out of a need to find physically healthy mates. A recent meta-analysis (Roberts and Little 2008) of studies on genes and attraction further supported these findings. They found that people see certain traits that are directly affected by one's genes, such as body size, height, and sexual 
dimorphic facial characteristics, as attractive. These metaanalyses provide a good basis on which to move on with the understanding that facial attraction can be tied to evolutionary adaptive traits and specific dimorphic characteristics found in males and females.

A great deal of research has been conducted directly on women's facial preferences in men. Penton-Voak et al. (2003) found that how attractive a woman found herself was an important factor as to what facial features the woman found attractive in men. These results suggest that women could possibly have much more diverse tactics in mate selection when compared to men. De Bruine et al. (2006) suggest that a woman's self-reported ideal mating partner and her real partner's masculinity had an effect on the type of face a woman preferred when looking at men. If their current partner had a very masculine face, women would tend to prefer more masculine faces, and if the woman's current partner had a more feminine face, the women found other men with feminine facial features attractive. Watkins et al. (2012) demonstrated that the perceived amount of social support an individual has directly affects their facial preferences. Faces that appear more feminine are perceived to be more supportive by both men and women. When asked to imagine a scenario where they receive little to no social support, individuals would then find faces that had more feminine traits as more attractive. This is applicable to women during situations where they perceive they need more social support, such as when the body is flooded with progesterone (during the menstrual cycle) (e.g., Jones et al. 2008; Penton-Voak et al. 1999). Combined with studies that have found that men are more focused on physical beauty in mate selection than women (e.g., Edlund and Sagarin 2010; Li et al. 2013), there is a clear illustration that different factors influence women and men in terms of finding someone attractive or not. These studies point to a possible difference in how men and women process and judge attractiveness. It appears that women are influenced by more factors when making an evaluation of someone's attractiveness.

It has also been demonstrated that external and internal facial characteristics play a part in facial processing and recognition and help us identify familiar and unfamiliar faces. Internal facial characteristics are the inner parts of the face like the eyes, nose, and mouth. Meanwhile, external facial characteristics would be the cheeks, chin, and forehead. Ellis et al. (1979) conducted one of the first studies looking at the importance of these facial features in facial recognition and processing. They suggested that internal features on familiar faces are encoded and processed to a greater degree than on unfamiliar faces. They hypothesized this is because of a need for people to process the emotions of familiar faces, which are mostly conveyed through the internal facial features.

Further illustrating the importance of external facial features in unfamiliar face recognition is research conducted by
Bruce et al. (1999). They found that participants overall were much worse at identifying an unfamiliar face in a video clip if an expression changed or if the viewing angle changed The researchers also discovered that when faces were matched correctly, it was usually because of a distinct external facial feature being visible in both the target picture and the photo participants had to match. This study further supports the findings of the Ellis et al. (1979) study but in a modern setting and with different forms of media, in this case video.

What all of these studies illustrate is that adults appear to perceive and process faces as wholes and not just as striking individual features, but the features we do focus on, whether they be internal or external, are influenced by familiarity. This is important to understand in the context of the current study as it asks participants to process faces and make judgments of unfamiliar faces. It also brings into light a question of disfigurement placement and if a disfigurement on the external part of an unfamiliar face would be noticed before a disfigurement on the inner part of the face, and if this difference would cause an effect on attraction scores.

\section{Hypotheses}

The first hypothesis proposed in this study is that participants who have the emotion of disgust induced will rate pictures of people as less attractive, in contrast to participants who are primed with neutral photos. The evolutionary importance of disgust as a moderator of behavior, as has been shown in previous research, and its importance in avoiding certain types of contagious diseases support this hypothesis (e.g., Oaten, et al. 2009; Park, et al. 2003; Ryan, et al. 2012). The current study, however, hopes to show how it affects our perceptions of attractiveness specifically as to the best of our knowledge, no studies have previously examined this issue.

The second hypothesis is that the pictures with facial disfigurements will be rated as less attractive than the other faces regardless of mood induction. Research has shown that facially disfigured individuals are actively avoided and socially stigmatized through this avoidance or staring behaviors (e.g., Halioua, et al. 2011; Houston and Bull 1994; Lawrence, et al. 2007; Kleck and Strenta 1985). Research on the importance of facial symmetry to ratings of attractiveness also supports this hypothesis as a facial disfigurement would increase facial asymmetry (Fink and Penton-Voak 2002; Johnson, et al. 2001; Schieb, et al. 1999).

The third hypothesis of the current work is that the location of the disfigurement (whether it is located on the periphery or central part of the face) will play a role in the rating of attractiveness as suggested in previous facial recognition and processing work (e.g., Bruce et al. 1999; Ellis et al. 1979). 


\section{Method}

\section{Participants}

Data from 61 participants were collected for this experiment; however, ten participants were excluded before analysis began. Nine of these participants were excluded because they were non-heterosexuals (it has been demonstrated that nonheterosexuals have different facial preferences than heterosexuals and as such they should be tested separately; e.g., Bailey, Kim, Hills, and Linsenmeier 1997; Glassenberg, Feinberg, Jones, Little, and DeBruine 2010). The last participant was excluded because they provided the same rating for every photo, suggesting that the participant did not pay attention to the photos. Principal analysis was done on 51 college students from a large private northeastern university (29 men, 22 women) with an age of $M_{\text {age }}=20.65, \mathrm{SD}=2.23$.

\section{Materials}

All participants in this experiment took part in a mood induction procedure. A mood induction is when participants have a particular emotion induced usually through some type of film or pictures and sometimes even reading aloud phrases (Polivy 1981). In particular, it has been shown that films, pictures, and music are effective methods of inducing a specific mood (e.g., Falkenberg, Kohn, Schoepker, and Habel 2012; Thake and Zelenski 2013; Weinberger and McKee 2012). The main instrument for this study was a computer program, which presented both induction stimuli and target photos to participants (DirectRT, Empirisoft, 2004). Following the example of previous research (e.g., Falkenberg, et al. 2012; Larsen and Ketelaar 1989; Mata, et al. 2013), the induction stimuli consisted of nine images for each of the three conditions: disgust induction, control, and hygiene. The disgust and neutral induction photos came from the International Affective Pictures System (IAPS; Lang, Bradley, and Cuthbert 2008) while the hygiene pictures were taken from the Internet. Hygiene was included to provide a foil to the disgust induction, in order to test for an opposite reaction in participants. The pictures used as induction stimuli were pre-rated in a pilot study on a scale of 1 to 7 ( 1 being the least of a characteristic, i.e., "not disgusting" and 7 being the most, i.e., "very disgusting"). The photos were rated on four different characteristics: disgust, cleanliness, positivity, and negativity. The pictures used in the disgust induction condition were rated as the most disgusting $(M=6.68)$ and the most negative $(M=5.26)$. They were also rated as the least clean and least positive $\left(M_{\text {clean }}=\right.$ $1.51, M_{\text {positive }}=1.83$ ). The pictures used in the hygiene condition were rated as the cleanest $(M=6.68)$ and the most positive $(M=6.08)$ and as the least disgusting and least negative $\left(M_{\text {disgust }}=1.07, M_{\text {negative }}=1.44\right)$. The pictures used in the neutral induction condition were rated as near the average when compared to the disgusting and hygienic pictures' average across all four conditions $\left(M_{\text {disgust }}=1.91, M_{\text {clean }}=3.44\right.$, $\left.M_{\text {positive }}=3.91, M_{\text {negative }}=2.97\right)$. All of the stimuli photos used in this experiment can be found in the supplemental file.

The pictures that participants rated for attractiveness consisted of 45 pictures in three different conditions: inner disfigured where a disfigurement was placed on the inner part of the face, outer disfigured where a disfigurement was placed on the outer part of the face, or not disfigured faces where the photo was unedited (no disfigurement). The faces were also one of three races (Caucasian, African-American, or Hispanic). All faces were the same size of $313 \times 385$ pixels and were all presented in the same aspect ratio on screen of $800 \times 600$ pixels. To put the disfigurements on the faces, photo-editing software was used. The disfigurements were different shapes but the same total size (by the percentage of the face) and were color matched to match the skin tone of the individual in the picture, and they were placed on either the outer (hairline, jawline) or inner (below eye, next to mouth) part of the face. These pictures were taken from the Florida State Penal Database where pictures of all parolees and prisoners are publicly available (see supplemental file for photos used in this study).

Because the differences in scores assigned to the target photos between mood induction conditions are the main focus of this study, it was imperative that the target photos be heterogeneously attractive across the race conditions. This would ensure that any differences found would be a result of the mood induction condition and not a result of faces of one race being more attractive as a whole than another. To accomplish this and determine the heterogeneity of the target photos, a repeatedmeasures ANOVA was run in which the scores assigned to every photo by every participant were compared against each other. This population was determined to be heterogeneous in terms of attractiveness of individual faces by this ANOVA $F(2$, 49) $=269.46, p<.01, \eta_{\mathrm{p}}{ }^{2}=.84$. The significant result suggests that no one group of target photos was made of photographs that were more attractive as a whole than another group (ensuring that any effects are not a result of a homogenously attractive/non-attractive sample; Rubenstein 2005).

At three points in the experiment, participants were asked to fill out a mood questionnaire detailing their mood at the moment. The moods they were asked about were happiness, disgust, frustration, surprise, and anger. Participants selfreported their mood on a Likert scale of 1 to 7 where 1 meant the participant did not feel a particular mood and 7 meant they felt the mood on an extreme level. This mood questionnaire served as a manipulation check.

\section{Procedure}

Participants came into the lab and were asked to sit in front of the computer they would use for the experiment. They were 
then given the consent form to read and sign. After consenting, participants filled out a demographic questionnaire and then the first of three mood questionnaires to determine their feelings prior to the mood induction. Participants filled out the mood questionnaire three times throughout the experiment $\left(T_{1}, T_{2}, T_{3}\right)$ with approximately $1-5 \mathrm{~min}$ in between each administration of the questionnaire depending on how quickly participants were able to make their attractiveness ratings. Following the completion of both the demographic and first mood questionnaire $\left(\mathrm{T}_{1}\right)$, participants were then randomly assigned into one of three induction groups: disgust induction $(N=18)$, hygiene induction $(N=16)$, or neutral induction $(N=17)$. Participants viewed each of the nine pictures in the condition twice in a set order. Each picture was visible to participants for $1 \mathrm{~s}$. This led to a total induction time of $18 \mathrm{~s}$. Following this presentation of induction materials, the participants then filled out the same mood questionnaire $\left(\mathrm{T}_{2}\right)$ as a manipulation check. Participants were then given instruction on how to properly rate the faces via DirectRT and allowed to continue the experiment. Each participant looked at 45 pictures, which were split by race and disfigurement condition. Each participant viewed 15 African-American, Hispanic, and Caucasian faces. Participants viewed only pictures of the gender they were attracted to (based on their answers to the demographic question of sexual orientation). Of these 15 pictures, 5 of the pictures would have a disfigurement on the inner part of the face, the outer part of the face, or no disfigurement at all. ${ }^{1,2}$ Participants were asked to rate the photos on a scale from 1 to 9 with 1 being very unattractive and 9 being very attractive. Additionally, we tracked reaction times for photo ratings. When all photos had been rated, participants filled out the mood questionnaire a final time $\left(T_{3}\right)$ and then were thanked for their time and dismissed.

\section{Results}

\section{Manipulation Check}

To determine if the inductions used in this experiment had the desired effect, an analysis was first conducted on the responses of participants to the mood questionnaire to verify that the manipulation had the desired effect. The mean mood scores can be found in Table 1. An omnibus analysis of variance was run looking at mood, time, induction condition, and gender. Significant effects were found between moods $F(4$, $42)=84.40, p<.01, \eta_{\mathrm{p}}{ }^{2}=0.89$, for mood and condition $F(8$,

\footnotetext{
${ }^{1}$ Due to a coding error, participants in the disgusting induction condition saw six inner-scarred black faces and four outer-scarred black faces and the participants in the neutral induction condition saw six outer-scarred black faces and four inner-scarred black faces.

${ }^{2}$ Due to an error in the computer program, participants in the neutral condition who looked at photos of women saw only 44 photos.
}

$38)=5.49, p<.01, \eta_{\mathrm{p}}{ }^{2}=0.54$, and for mood, condition, and time $F(16,76), p<.01, \eta_{\mathrm{p}}{ }^{2}=0.46$. These results suggest that the mood induction had the desired impact on participants.

\section{Primary Analyses}

In order to test if there was an interaction between disfigurement and mood induction procedure, a mixed-measures ANOVA was run comparing attraction scores of the disfigured versus non-disfigured faces with between-subjects factors of mood induction condition and gender. There was a significant main effect which showed that disfigured faces in general were found to be less attractive than non-disfigured faces $F(1,45)=20.876, p<.01, \eta_{\mathrm{p}}{ }^{2}=.32$ (Table 2). The results also showed a significant interaction between the disfigurement of the faces and mood induction condition $F(2,45)=4.173$, $p<.05, \eta_{\mathrm{p}}{ }^{2}=.16$. Participants who underwent the neutral mood induction generally rated faces higher than participants in both the hygiene and disgust conditions $\left(M_{\text {disfigured }}=3.23, M_{\text {non- }}\right.$ disfigured $=3.60), F(1,16)=10.70, p=.005$. Meanwhile, the participants who underwent the hygiene induction $\left(M_{\text {disfigured }}=\right.$ $\left.3.00, M_{\text {non-disfigured }}=3.06\right), F(1,15)=.03, p>.05$ and the disgusted mood induction $\left(M_{\text {disfigured }}=3.02, M_{\text {non-disfigured }}=\right.$ 3.47), $F(1,17)=10.42, p=.005$ rated photographs lower than the participants who underwent the neutral mood induction. These results suggest that participants who had either the hygiene or the disgusted mood-induced rated disfigured photographs significantly lower than participants who took part in the neutral mood induction.

An overall effect was found between all three of the factors (disfigurement, mood induction condition, and gender) as well $F(2,45)=7.091, p<.01, \eta_{\mathrm{p}}{ }^{2}=.24$. Women in general rated

Table 1 Mean mood ratings at time 1,2, and 3. Moods rated on a scale of 1 to 7

\begin{tabular}{llllllll}
\hline Condition & Mood & $M_{\text {time 1 }}$ & $\mathrm{SD}$ & $M_{\text {time 2 }}$ & $\mathrm{SD}$ & $M_{\text {time } 3}$ & $\mathrm{SD}$ \\
\hline \multirow{2}{*}{ Neutral } & Disgust & 1.412 & 1.004 & 1.412 & 1.004 & 2.000 & 1.275 \\
& Happiness & 4.882 & 1.269 & 4.824 & 1.424 & 4.412 & 1.204 \\
& Anger & 1.529 & 1.289 & 1.529 & 1.125 & 1.412 & 1.004 \\
& Frustration & 2.471 & 1.940 & 2.294 & 1.929 & 1.882 & 1.765 \\
& Surprise & 1.765 & 1.640 & 1.941 & 1.600 & 2.000 & 1.323 \\
Hygiene & Disgust & 1.375 & 0.885 & 1.125 & 0.500 & 1.688 & 0.873 \\
& Happiness & 4.750 & 1.390 & 4.813 & 1.424 & 4.375 & 1.204 \\
& Anger & 1.938 & 1.289 & 1.938 & 1.181 & 1.875 & 1.204 \\
& Frustration & 2.813 & 1.721 & 2.438 & 1.632 & 2.188 & 1.515 \\
& Surprise & 1.813 & 1.471 & 1.750 & 1.390 & 2.188 & 1.559 \\
Disgusting & Disgust & 1.000 & 0.000 & 4.333 & 1.910 & 1.944 & 1.434 \\
& Happiness & 5.278 & 0.669 & 4.389 & 1.577 & 4.333 & 1.455 \\
& Anger & 1.500 & 0.707 & 1.556 & 1.042 & 1.333 & 0.767 \\
& Frustration & 2.111 & 1.451 & 1.944 & 1.765 & 1.722 & 1.179 \\
& Surprise & 1.667 & 1.029 & 3.778 & 2.016 & 1.889 & 1.183 \\
\hline
\end{tabular}


Table 2 Attractiveness scores of disfigured vs. non-disfigured photographs by mood induction condition

\begin{tabular}{lllll}
\hline Mood induction condition & $M_{\text {disfigured }}$ & SD & $M_{\text {non-disfigured }}$ & SD \\
\hline Neutral & 3.23 & 0.84 & 3.60 & 0.78 \\
Hygiene & 3.00 & 1.08 & 3.06 & 1.09 \\
Disgusting & 3.02 & 1.04 & 3.47 & 1.10 \\
\hline
\end{tabular}

photos lower than did men for both disfigured and nondisfigured faces; however, women were more affected by the mood induction condition than were men for both disfigured faces and for normal faces. For the full results, please see Table 3. These results suggest that women are more affected by mood when they determine the attractiveness of an individual.

To determine if the location of the disfigurement mattered, another mixed-measures ANOVA was run, this time looking only at scores given to both outer-scarred photos $(M=3.10$, $\mathrm{SD}=1.01)$ and the inner-scarred photos $(M=3.07, \mathrm{SD}=1.00)$, $F(1,48)=0.39, p>0.5, \eta_{\mathrm{p}}{ }^{2}=.008$. This suggests that no matter where the scar is placed, people will find a disfigured face as unattractive when compared to a face without a disfigurement.

\section{Discussion}

The significant differences in the mood questionnaire following the disgusting mood induction demonstrate that the disgust induction was successful in creating feelings of disgust in participants. Further, the attractiveness ratings participants in the disgusted condition gave were significantly lower than the ratings given to photos following a neutral mood induction (thus supporting the first hypothesis). Surprisingly, the ratings given by the participants in the cleanliness condition were also lower. We believe this trend could have occurred as the pictures used to induce hygiene included photos of hand soap and people washing their hands which has been shown to actually induce feelings of needing to wash ones hands (Nichols 2014). Further, research has shown that a way to increase use of hand sanitizer stations is to make people more aware of the germs on their person (Updegraff, Emanuel, Gallagher, and Steinman 2011). As such, this could have affected the mindset of participants in the hygiene condition, leading to the lower ratings of attractiveness.

The second hypothesis of this study was that the faces with disfigurements would be rated as less attractive than the faces without disfigurements. The results support this hypothesis as all of the disfigured faces received lower attractiveness scores than the non-disfigured faces. This finding has previously been demonstrated, and the current study provides more support towards the fact that people find them less attractive, which may lead to avoidance (e.g., Halioua, et al. 2011; Houston and Bull 1994). Although this basic effect has been demonstrated in previous research, our study extends this literature by demonstrating that the location of the disfigurement on the face does not have a differential influence on attractiveness.

One potential limitation of the current study is the mood induction procedure and the lack of arousal measures taken. Previous research has shown that pictures that are arousing in a specific manner (e.g., motivating) create a stronger mood effect in participants (Bradley, Codispoti, Cuthbert, and Lang 2001). If any of the pictures used in this experiment were or were not arousing in a specific manner, then one picture could have had a bigger impact than any other photo on a participant's mood. Another limitation of the current study could be in the target photographs themselves. The potential issue with these photos is that they all were of criminals who were recently put on parole in the state of Florida. The use of photographs of criminals is an issue because as research first conducted by Thornton (1939) and more recently by Valla, Ceci, and Williams (2011) suggests, people are adept at picking out criminals when are given pictures. It is possible that these phenomena may explain the generally mid-range ratings of attractiveness across all conditions in the study. Another limitation of the current study is that recent research has shown that an individual's perceived vulnerability to disease can affect their facial preferences. It has been shown that an individual will prefer healthy traits in a face if they believe they are more vulnerable to disease (Welling, Conway, DeBruine, and Jones 2007). Because of this fact, perceived
Table 3 Attractiveness scores of disfigured vs. non-disfigured photos by participant sex

\begin{tabular}{llllll}
\hline Participant sex & Mood induction condition & $M_{\text {disfigured }}$ & SD & $M_{\text {non-disfigured }}$ & SD \\
\hline Male & Neutral & 3.58 & 0.83 & 3.73 & 0.69 \\
& Hygiene & 3.15 & 0.95 & 3.44 & 0.73 \\
& Disgust & 3.21 & 0.81 & 3.86 & 1.13 \\
Female & Overall & 3.32 & 0.85 & 3.69 & 0.86 \\
& Neutral & 2.74 & 0.60 & 3.43 & 0.93 \\
& Hygiene & 2.81 & 1.27 & 2.57 & 1.32 \\
& Disgust & 2.78 & 1.29 & 2.99 & 0.90 \\
& Overall & 2.78 & 1.06 & 2.99 & 1.06 \\
\hline
\end{tabular}


vulnerability to disease measurements should be taken of each participant in future research.

The current study's results demonstrate that being disgusted will affect how attractive an individual finds another person. The results also reaffirm that facial disfigurement is seen as less attractive compared to faces not marred by disfigurements and that the location of the disfigurement on the face does not play a role in the subsequent decrease in attractiveness. The research also demonstrates that men and women do have differences when it comes to rating the attractiveness of faces and, in fact, women tend to rate faces lower than men do.

Acknowledgments The data reported in this study were part of the first author's master's thesis. We would like to thank Joseph Baschnagel, Tina Sutton, and Andrew Herbert for all the help they provided in the degree program. We also wish to thank the anonymous reviewers for their helpful comments which helped us improve the manuscript.

\section{References}

Bailey, J. M., Kim, P. Y., Hills, A., \& Linsenmeier, J. A. W. (1997). Butch, femme, or straight acting? Partner preferences of gay men and lesbians. Journal of Personality and Social Psychology, 73(5), 960973.

Bradley, M. M., Codispoti, M., Cuthbert, B. N., \& Lang, P. J. (2001). Emotion and motivation I: defensive and appetitive reactions in picture processing. Emotion, 1(3), 276-298. doi:10.1037/15283542.1.3.276

Bruce, V., Henderson, Z., Greenwood, K., Hancock, P. J. B., Burton, A. M., \& Miller, P. (1999). Verification of face identities from images captured on video. Journal of Experimental Psychology: Applied, 5(4), 339-360.

Buss, D. M., \& Schmitt, D. P. (1993). Sexual strategies theory: an evolutionary perspective on human mating. Psychological Review, 100(2), 204-232. doi:10.1037/0033-295X.100.2.204.

De Bruine, L. M., Jones, B. C., Little, A. C., Boothroyd, L. G., Perrett, D. I., Penton-Voak, I. S., \& Tiddeman, B. P. (2006). Correlated preferences for facial masculinity and ideal or actual partner's masculinity. Proceedings of the Royal Society B: Biological Sciences, 273, 13551360. doi:10.1098/rspb.2005.3445.

DirectRT (Version 2004.1.0.55) [Computer software on CD-ROM]. (2004). New York, NY: Empirisoft

Edlund, J. E. \& Sagarin, B. J. (2010). Mate value and mate preferences: An investigation into decisions made with and without constraints. Personality and Individual Differences, 49, 835-839.

Ellis, H. D., Shepherd, J. W., \& Davies, G. M. (1979). Identification of familiar and unfamiliar faces from internal and external features: some implications for theories of face recognition. Perception, 8 , 431-439.

Falkenberg, I., Kohn, N., Schoepker, R., \& Habel, U. (2012). Mood induction in depressive patients: a comparative multidimensional approach. Public Library of Science ONE, 7(1), 1-9.

Fink, B., \& Penton-Voak, I. (2002). Evolutionary psychology of facial attractiveness. Current Directions in Psychological Science, 11, 154-158. doi:10.1111/1467-8721.00190.

Glassenberg, A. N., Feinberg, D. R., Jones, B. C., Little, A. C., \& DeBruine, L. M. (2010). Sex-dimorphic face shape preference in heterosexual and homosexual men and women. Archives of Sexual Behavior, 39, 1289-1296. doi:10.1007/s10508-009-9559-6.
Griffey, J. F., \& Little, A. C. (2014). Similarities in human visual and declared measures of preference for opposite-sex faces. Experimental Psychology, 61(4), 301-309. doi:10.1027/16183169/a000248.

Halberstadt, J., \& Rhodes, G. (2000). The attractiveness of nonface averages: implications for an evolutionary explanation of the attractiveness of average faces. Psychological Science, 11(4), 285-289.

Halioua, R. L., Williams, R. S. T., Murray, N. P., Skalko, T. K., \& Vogelsong, H. G. (2011). Staring and perceptions of people with facial disfigurement. Therapuetic Recreation Journal, 45(4), 341356.

Houston, V., \& Bull, R. (1994). Do people avoid sitting next to someone who is facially disfigured? European Journal of Social Psychology, 24(2), 279-284.

Johnson, V. S., Hagel, R., Franklin, M., Fink, B., \& Grammer, K. (2001). Male facial attractiveness: evidence for hormone mediated adaptive design. Evolution and Human Behavior, 22, 251-267.

Jones, B. C., Debruine, L. M., Perret, D. I., Little, A. C., Feinberg, D. R., \& Law Smith, M. J. (2008). Effects of menstrual cycle phase on face preferences. Archives of Sexual Behavior, 37, 78-84. doi:10.1007/ s10508-007-9268-y.

Kleck, R. E., \& Strenta, A. C. (1985). Gender and responses to disfigurement in self and others. Journal of Social and Clinical Psychology, 3(3), 257-267.

Kurzban, R., \& Leary, M. (2001). Evolutionary origins of stigmatization: the functions of social exclusion. Psychological Bulletin, 127(2), 187-208. doi:10.1037//0033-2909.127.2.187.

Lang, P. J., Bradley, M. M., \& Cuthbert, B. N. (2008). International affective picture system (IAPS): affective ratings of pictures and instruction manual (Technical Report A-8). Gainesville: University of Florida.

Larsen, R. J., \& Ketelaar, T. (1989). Extraversion, neuroticism and susceptibility to positive and negative mood induction procedures. Personality and Individual Differences, 10(12), 1221-1228.

Lawrence, J. W., Rosenberg, L. E., \& Fauerbach, J. A. (2007). Comparing the body esteem of pediatric survivors of burn injury with the body esteem of an age-matched comparison group without burns. Rehabilitation Psychology, 52(4), 370-379.

Li, N. P., Yong, J. C., Tov, W., Sng, O., Fletcher, G. O., Valentine, K. A., \& Balliet, D. (2013). Mate preferences do predict attraction and choices in the early stages of mate selection. Journal of Personality And Social Psychology, 105(5), 757-776. doi:10.1037/ a0033777.

Mata, J., Hogan, C. L., Joorman, J., Waugh, C. E., \& Gotlib, I. H. (2013). Acute exercise attenuates negative affect following repeated sad mood inductions in persons who have recovered from depression. Journal of Abnormal Psychology, 122(1), 45-50. doi:10.1037/ a0029881.

Nichols, A. L. (2014). Actual vs. reported behavior: Increasing handwashing in public restrooms. Swiss Journal of Psychology, 73(1), 41-46.

Oaten, M., Stevenson, R. J., \& Case, T. I. (2009). Disgust as a diseaseavoidance mechanism. Psychological Bulletin, 135(2), 303-321. doi:10.1037/a0014823.

Park, J. H., Faulkner, J., \& Schaller, M. (2003). Evolved diseaseavoidance processes and contemporary anti-social behavior: prejudicial attitudes and avoidance of people with physical disabilities. Journal of Nonverbal Behavior, 27(2), 65-87.

Penton-Voak, I. S., Jones, B. C., Little, A. C., Baker, S., Tiddeman, B., Burt, D. M., \& Perrett, D. I. (2001). Symmetry, sexual dimorphism in facial proportions and male facial attractiveness. Proceedings of the Royal Society of London. Series B: Biological Sciences, 268, 1617-1623. doi:10.1098/rspb.2001.1703.

Penton-Voak, I. S., Little, A. C., Jones, B. C., Burt, D. M., Tiddeman, B. P., \& Perrett, D. I. (2003). Female condition influences preferences for sexual dimorphism in faces of male humans (Homo sapiens). 
Journal of Comparative Psychology, 117(3), 264-271. doi:10.1037/ 0735-7036.117.3.264.

Penton-Voak, I. S., Perret, D. I., Castles, D. L., Kobayashi, T., Burt, D. M., Murray, L. K., \& Minamisawa, R. (1999). Menstrual cycle alters face preference. Nature, 399, 741-742.

Polivy, J. (1981). On the induction of emotion in the laboratory: discrete moods or multiple affect states? Journal of Personality and Social Psychology, 41(4), 803-817.

Rhodes, G. (2006). The evolutionary psychology of facial beauty. Annual Review of Psychology, 57, 199-226. doi:10.1146/annurev.psych.57. 102904.190208.

Roberts, S. C., \& Little, A. C. (2008). Good genes, complementary genes and human mate preferences. Genetica, 132, 309-321. doi:10.1007/ s10709-007-9174-1.

Ryan, S., Oaten, M., Stevenson, R. C., \& Case, T. I. (2012). Facial disfigurement is treated like an infectious disease. Evolution and Human Behavior, 33, 639-646.

Rubenstein, A. J. (2005). Variation in perceived attractiveness. Psychological Science, 16(10), 759-762. doi:10.1111/j.1467-9280. 2005.01610.x.

Schieb, J. E., Gangestead, S. W., \& Thornhill, R. (1999). Facial attractiveness, symmetry, and cues of good genes. Proceedings of the Royal Society of London Series B: Biological Sciences, 266, 1913-1917.

Thake, J., \& Zelenski, J. M. (2013). Neuroticism, BIS, and reactivity to discrete negative mood inductions. Personality and Individual Differences, 54, 208-213. doi:10.1016/j.paid.2012.08.041.
Thornton, G. R. (1939). The ability to judge crimes from photographs of criminals: a contribution to technique. Journal of Abnormal and Social Psychology, 1, 378-383.

Tybur, J. M., Liberman, D., \& Griskevicius, V. (2009). Microbes, mating and morality: individual differences in three functional domains of disgust. Journal of Personality and Social Psychology, 97(1), 103122. doi:10.1037/a0015474.

Tybur, J. M., Lieberman, D., Kurzban, R., \& DeScioli, P. (2013). Disgust: evolved function and structure. Psychological Review, 120(1), 6584. doi: $10.1037 / \mathrm{a} 0030778$.

Updegraff, J. A., Emanuel, A. S., Gallagher, K. M., \& Steinman, C. T. (2011). Framing flu prevention - an experimental field test of signs promoting hand hygiene during the 2009-2010 H1N1 pandemic. Health Psychology, 30(3), 295-299. doi:10.1037/a0023125.

Valla, J. M., Ceci, S. J., \& Williams, W. M. (2011). The accuracy of inferences about criminality based on facial appearance. Journal of Social, Evolutionary, and Cultural Psychology, 5(1), 66-91.

Watkins, C. D., DeBruine, L. M., Little, A. C., \& Jones, B. C. (2012). Social support influences preferences for feminine facial cues in potential social partners. Experimental Psychology, 59(6), 340 347. doi:10.1027/1618-3169/a000162.

Welling, L. L. M., Conway, C. A., Debruine, L. M., \& Jones, B. C. (2007). Perceived vulnerability to disease is positively related to the strength of preferences for apparent health in faces. Journal of Evolutionary Psychology, 5(1), 131-139. doi:10.1556/JEP.2007.1012.

Weinberger, A. H., \& McKee, S. A. (2012). Gender differences in smoking following an implicit mood induction. Nicotine \& Tobacco Research, 14(5), 621-625. doi:10.1093/ntr/ntr198. 